Letrônica, Porto Alegre, v. 7, n. 1, p. 179-197, jan./jun., 2014

\title{
AVALIAÇÃO E ENSINO DA COMPREENSÃO LEITORA: CONTRIBUIÇÕES DO CAMPO DA PSICOLINGUÍSTICA À EDUCAÇÃO*
}

\author{
EVALUATION AND READING COMPREHENSION INSTRUCTION: \\ CONTRIBUTIONS FROM PSYCHOLINGUISTICS TO THE EDUCATION
}

\author{
Clarice Lehnen Wolff** \\ Marília Marques Lopes ${ }^{* * *}$
}

\begin{abstract}
Resumo: Este artigo trata da compreensão da leitura e de sua avaliação. São abordados, a partir de revisão teórica no campo da Psicolinguística, os processos básicos de leitura na relação leitor-texto, com destaque aos processamentos ascendente e descendente e sua interação, na busca pela construção de sentido. Estes se desdobram, a partir da alfabetização, em direção a leituras que exigem inferências mais elaboradas, desenvolvidas de forma explícita e implícita. São enfocados aspectos metalinguísticos que devem ser conhecidos pelo professor na elaboração de atividades que orientem seus alunos a um desenvolvimento mais aprofundado dos seus processos de compreensão leitora. Os diferentes níveis linguísticos do texto e as diferentes estratégias cognitivas acionadas pelo aluno, de acordo com a atividade proposta, precisam ser levados em conta nos processos de ensino e avaliação.
\end{abstract}

Palavras-chave: Leitura; Compreensão; Avaliação; Ensino.

\begin{abstract}
The present paper addresses reading comprehension and its evaluation. The goal is to address, based on a theoretical review within the field of Psycholinguistics, the basic processes in the reader-text relationship; the study addresses, especially, top-down and bottom-up processes in the search for the construction of meaning. These processes develop from early alphabetization to later reading comprehension processes that require more sophisticated inference-making based, in turn, on implicit and explicit information. We discuss the metalinguistic aspects which should be made available to elementary school teachers so that they can develop activities aimed at helping readers achieve a deeper understanding of their comprehension processes. Different linguistic levels of texts and different cognitive strategies, used according to the activities proposed, should be taken into consideration in teaching and evaluation processes.
\end{abstract}

Keywords: Reading; Comprehension; Evaluation; Teaching.

\footnotetext{
${ }^{*}$ Este artigo teve sua fundamentação baseada em capítulos das teses de doutoramento em construção das autoras, a serem defendidas até o mês de janeiro de 2015.

${ }^{* *}$ Doutoranda em Linguística da FALE-PUCRS. E-mail: clarice.lewolff@gmail.com.

*** Doutoranda em Linguística da FALE-PUCRS. E-mail: liamarilopes@gmail.com.
} 


\section{Introdução}

Os processos cognitivo-linguísticos envolvidos na compreensão de textos são objeto de significativos estudos do campo da Psicolinguística. Os conceitos já desenvolvidos nessa área do conhecimento são, ou deveriam ser, importante referência para a área da Educação, pois possibilitam conhecer com mais propriedade como os alunos estão desenvolvendo seu aprendizado de leitura, e também auxiliam a aprimorar recursos metodológicos em sala de aula, tanto para o ensino como para a avaliação da compreensão leitora. 0 crescente número de pesquisas em interface entre a Psicolinguística e a Educação tem procurado subsidiar as práticas em sala de aula, fornecendo resultados concretos e consistentes para aqueles que se interessam pelo aperfeiçoamento do seu fazer pedagógico.

Este artigo apresenta alguns dos principais conceitos relacionados ao processamento da compreensão leitora, na área da Psicolinguística. São destacados autores basilares da área e alguns dos estudos experimentais atuais, que possibilitam discutir implicações pedagógicas quanto a diferentes aspectos cognitivo-linguísticos acionados no processo de compreensão textual pelos aprendizes em tarefas apresentadas pela escola - elaboração de resumos, respostas a perguntas inferenciais, entre outras atividades que costumam ser desenvolvidas em sala de aula.

\section{Conceitos relacionados ao processo de compreensão leitora}

“A compreensão da leitura não pode ser absolutamente medida, já que não é a quantidade de qualquer coisa", pondera Smith (2003). Para esse autor, um dos mais conhecidos estudiosos na área da Psicolinguística, a compreensão é mais apropriadamente um estado, o oposto de confusão. Ela corresponde à "possibilidade de se relacionar o que quer que estejamos observando no mundo à nossa volta, ao conhecimento, intenções e expectativas que já possuímos em nossas cabeças" (idem, p. 72). Assim, a compreensão da leitura existe quando há a extração de sentido do texto, relacionando o que já se conhece com aquilo que se quer saber ou experimentar. 
Goodman (1976) descreve o ato de ler como uma atividade de reconstrução do texto pelo leitor através das pistas colocadas pelo escritor. Esse autor destaca que para a leitura é importante o objetivo do leitor, sua cultura social, seu conhecimento prévio, seus esquemas linguísticos e conceituais. Essa atividade de reconstrução textual é afetada pelas inferências, referências e correferências trazidas pelos esquemas cognitivos do leitor (GOODMAN, 1991, p. 28). Assim, diferentes pessoas lendo o mesmo texto podem apresentar variações no que se refere à compreensão deste, segundo a natureza de suas contribuições pessoais ao significado.

Hoje são conhecidos dois processamentos básicos por parte do leitor no processo de leitura, que ocorrem em interação ${ }^{1}$, de maneira complementar, podendo haver o predomínio de um sobre o outro em determinados momentos e de acordo com o objetivo da leitura realizada. São eles: o processamento ascendente ou bottom-up e o processamento descendente ou top-down.

0 conceito tradicional dessas formas de processamento da leitura destaca os seguintes aspectos:

- com o processamento ascendente se faz uso linear e indutivo das informações visuais e linguísticas, pois sua abordagem é composicional, isto é, acessa-se o significado através da análise e síntese do significado das partes (KATO, 2007, p. 50). Predomina quando o leitor constrói o significado com base nos dados do texto, fazendo pouca leitura nas entrelinhas. Ele realiza um papel de analisador, pois se atém a palavras e frases para formar sua compreensão (KATO, 1990), detectando até mesmo erros de ortografia. 0 predomínio deste tipo de processamento torna a leitura vagarosa e pouco fluente, gerando dificuldades na identificação das ideias principais do texto. Como sintetizado por Pereira e ScliarCabral (2012, p. 37), o leitor faz o movimento da informação do texto à cognição.

- o processamento descendente é uma abordagem não linear, com a qual o leitor faz uso intensivo e dedutivo de informações não visuais e cuja direção é da macro para a microestrutura (KATO, 2007, p. 50). Predomina quando o indivíduo apreende facilmente as ideias gerais e principais do texto, mostrando fluência e

\footnotetext{
1 Até a década de 80 havia grande divergência entre quem defendia os modelos ascendente ou descendente de leitura. McClelland e Rumelhart (1981) propuseram, então, o modelo interativo no processamento da leitura, integrando os processos ascendente e descendente como subprocessos utilizados pelo leitor para identificação de sentidos no texto (COLOMER; CAMPS, 2008, p. 42).
} 
velocidade, mas fazendo excessivas adivinhações, sem procurar confirmá-las com os dados do texto. Conforme Pereira e Scliar-Cabral (2012, p. 37), o leitor faz o movimento que provém dos conhecimentos prévios ${ }^{2}$ armazenados nas várias memórias, sejam eles linguísticos ou extralinguísticos. 0 processamento descendente prevalece entre leitores proficientes, que utilizam seu conhecimento de mundo e mobilizam seus esquemas cognitivos para compreender e antever situações no decorrer da leitura (KATO, 1990).

Colomer e Camps (2008), enfocando o processamento da informação, consideram que as duas formas de proceder na leitura, de baixo para cima e de cima para baixo, são englobadas na ideia básica de que, "quando uma pessoa lê, parte da hipótese de que o texto possui um significado e busca-o por meio da descoberta de indícios visuais, como da ativação de uma série de mecanismos mentais que permitem atribuir-lhe um sentido" (idem, p. 31). Essas autoras destacam o papel ativo do leitor na sua relação com o texto, da seguinte forma:

\begin{abstract}
Nos modelos interativos o leitor é considerado como um sujeito ativo que utiliza conhecimentos de tipo muito variado para obter informação do escrito e que reconstrói o significado do texto ao interpretá-lo de acordo com seus próprios esquemas conceituais e a partir de seu conhecimento do mundo. A relação entre o texto e o leitor durante a leitura pode ser qualificada como dialética: o leitor baseia-se em seus conhecimentos para interpretar o texto, para extrair um significado, e esse novo significado, por sua vez, permite-lhe criar, modificar, elaborar e incorporar novos conhecimentos em seus esquemas mentais. (COLOMER; CAMPS, 2008, p. 31).
\end{abstract}

O período da alfabetização, pode-se afirmar, é uma fase em que o processamento ascendente tem um forte predomínio com relação ao descendente. Um aspecto a ser enfatizado é o de que, para a efetivação da leitura, é fundamental que os processos de decodificação sejam bem desenvolvidos, com relações entre fonemas e grafemas bem estabelecidas, garantindo a fluência necessária para permitir que se acesse e compreenda o conteúdo lido. Para dominar esse processo, os recursos de atenção e memória são bastante exigidos do pequeno leitor durante a alfabetização. A este respeito, Dehaene (2012) chama a atenção para os erros de regularização que costumam ocorrer na aprendizagem da leitura:

\footnotetext{
${ }^{2}$ Os conhecimentos prévios são organizados em redes hierarquizadas que se conectam internamente entre si - os esquemas cognitivos, que resultam de representações do mundo que são internalizadas pelo indivíduo (PEREIRA; SCLIAR-CABRAL, 2012, p. 37).
} 


\begin{abstract}
A aprendizagem dos grafemas chama a atenção sobre a classe de sons; a análise das classes de sons afina, por seu turno, a compreensão dos grafemas e assim, em sequência, uma espiral causal faz emergir simultaneamente o código grafêmico e o código fonêmico. (...) O leitor debutante sabe ler algumas letras e transformá-las em sons, mas fracassa quando as palavras são irregulares: diante da palavra "fixo", ele lê, por exemplo, como se tivesse escrito "ficho", ao invés de /fikisu/. Outro sintoma é o efeito da complexidade silábica: o debutante sabe ler as sílabas simples formadas por uma consoante e uma vogal (CV), mas experimenta dificuldades crescentes à medida que aumenta o número de consoantes (CVC, CCVC, e assim por diante). (DEHAENE, 2012, p. 221).
\end{abstract}

Após a assimilação do processo de decodificação, muitas variáveis concorrem para uma leitura bem-sucedida do indivíduo, entre elas o conhecimento do contexto comunicativo, o conhecimento linguístico e o extralinguístico, advindos do processamento descendente. Este permite que o leitor, em seu papel ativo durante a leitura, faça uso, mesmo sem perceber, do seu aparato de conhecimentos que possibilitam construir a compreensão de textos.

Com respeito ao desenvolvimento das estratégias de leitura utilizadas pela criança no período inicial de escolaridade, a psicóloga Uta Frith (1985) identificou no desenvolvimento da leitura as seguintes fases: 1) pictórica, quando a criança ainda não compreendeu a lógica da escrita e faz o reconhecimento das palavras de forma global, explorando os traços visuais; 2) fonológica, quando ocorre a associação da cadeia de palavras à sua pronúncia, pela conversão fonema-grafema, desaparecendo o tratamento global da palavra; 3) ortográfica, quando ocorre a identificação visual das palavras por seu conjunto de letras e o tempo de leitura já não depende mais do tamanho da palavra ou de sua complexidade, mas principalmente da frequência com que a palavra aparece na língua. Stanislas Dehaene $^{3}$ (2012, p. 217) pondera que essas etapas não são distribuídas de forma rígida e que, continuamente, a criança passa de uma etapa a outra, numa escala de alguns meses a alguns anos.

Goodman (1991) contribui para o entendimento de como se dá a construção de sentido a partir da leitura, destacando sete aspectos cognitivos envolvidos neste processo, que são: iniciação ou reconhecimento da tarefa, ou seja, a decisão explícita de ativar as estratégias e esquemas apropriados para a leitura; amostragem e seleção, ou o direcionamento da atenção aos dados relevantes que se deseja decodificar; inferência, isto é, uma estratégia geral de adivinhação (termo adotado pelo próprio autor), com

\footnotetext{
${ }^{3}$ Este pesquisador destaca os correlatos cerebrais destas etapas de leitura, em seu livro "Neurônios da Leitura" (2012 - capítulo 5).
} 
base no que é conhecido, de qual informação é necessária embora não seja explícita, utilizada durante o processo de leitura; predição, ou a habilidade de antecipar o que está por vir e, assim, fazer com que o processo flua suavemente à medida que o leitor constrói texto e sentido, pois, ao contrário, o processamento seria sempre retrospectivo; confirmação e desconfirmação, que corresponde à automonitoração feita durante a leitura com relação às inferências e predições feitas, que são especulativas; correção, uma estratégia para recuperação do sentido na reconstrução do texto; e finalização, quando se toma a decisão de interromper ou finalizar a leitura. Dessas estratégias cognitivas, que estão na base do processo de compreensão, são destacadas duas principais, a predição e a habilidade de realizar inferências, que parecem abarcar outras estratégias mais pontuais (PEREIRA; SCLIAR-CABRAL, 2012).

A predição se refere à habilidade de antecipar o que está por vir, colaborando para o avanço da fluência do processo de construção do texto e do sentido. Baseia-se nos diferentes planos linguísticos, considerando conhecimentos prévios e as pistas linguísticas presentes no texto (semânticas, sintáticas, fonológicas, morfológicas, pragmáticas), orientando expectativas e hipóteses no processo da leitura. Os conhecimentos prévios estão intimamente ligados aos chamados esquemas cognitivos.

O conhecimento presumido do leitor constitui sua estrutura cognitiva. Leffa (1996) relaciona esse background aos esquemas, ou estruturas abstratas construídas pelo próprio sujeito e que representam sua teoria de mundo. Tais esquemas são formados por uma conjunção de variáveis, e a compreensão ocorre quando o leitor lhes atribui valores. Exemplificando, temos o esquema para "viagem de avião", que inclui variáveis como uma fila para check-in no aeroporto, malas sendo despachadas, espera para embarque e acomodação na aeronave, por exemplo. O esquema desse tipo de acontecimento presente na estrutura cognitiva do leitor permite que este represente mentalmente o evento. Mesmo não tendo experienciado uma viagem de avião, o fato de conhecer, seja por meio de imagens ou relatos, lhe permite estabelecer uma ligação entre o que já sabe e o que se apresenta durante uma leitura ou relato.

O uso da inteligência artificial em pesquisas na área da linguagem tem papel importante para se comprovar que é necessário aliar informações tanto linguísticas quanto extralinguísticas para a efetivação da compreensão. Através do trabalho com textos por computadores na geração de respostas a perguntas, evidencia-se que os 
mesmos devem ser alimentados com informações relativas ao léxico e sintaxe, bem como sobre o conhecimento do mundo. A teoria dos esquemas sugere que são formadas unidades de sentido correlacionando esses aspectos, possibilitando assim a formação de padrões de eventos, tais como "casamento", "aula" ou "carnaval”, os quais irão orientar a compreensão do leitor. Os esquemas, portanto, auxiliam na identificação, descrição e acionamento das unidades de sentido mais amplas.

A estratégia de realizar inferências é a que permite supor sentidos com base no que é conhecido, completando as lacunas ou indícios deixados pelo autor no texto, sem que haja a necessidade de ele explicar detalhadamente cada ideia escrita. Para isso, o leitor precisa dispor de informações suficientes no texto - as chamadas pistas linguísticas: aspectos fonéticos, fonológicos, morfológicos, semânticos, sintáticos e pragmáticos - que permitam estabelecer pontes de sentido coerentes naquilo que lê.

Spinillo e Mahon (2007) referem que a compreensão textual é um processo inferencial por excelência, uma vez que nem tudo o que está no texto é explicitado. Esta habilidade é a responsável pela formação de sentidos e pela representação mental organizada e coerente do texto. Kleiman (1989) também menciona que vários estudos mostram que o que o leitor lembra mais tarde, após a leitura, são as inferências que fez durante a mesma, e não o que o texto dizia literalmente. Importante salientar, para fins escolares, que, ainda que inferir permita ao leitor certa flexibilidade, por sua parcela ativa nesse processo, a compreensão apropriada é direcionada pelo próprio texto, não sendo possível inferir qualquer coisa (SPINILLO; MAHON, 2007).

Em função disso, o trabalho textual precisa ser minucioso e aprofundado. Pereira $(2010 ; 2012)$ oferece estratégias para esta tarefa de exploração de textos, ao agregar elementos que afirmam que a atividade de leitura deve estar vinculada ao desenvolvimento da consciência linguística ${ }^{4}$ do aluno, o que supõe a reflexão sobre as pistas fônicas, mórficas, sintáticas, semânticas, pragmáticas e textuais deixadas pelo autor. Esse trabalho deve ser associado tanto à atividade leitora como à de escrita. Essa autora enfatiza que "há uma convicção que está até no senso comum de que a leitura é importante para a escrita". No entanto, na escola isso nem sempre se traduz em um

\footnotetext{
4 "A consciência linguística ou conhecimento metalinguístico é a capacidade para pensar ou refletir sobre a expressão linguística; se refere à tomada da própria língua como objeto para cognição. Esta capacidade permite ao sujeito poder pensar sobre a linguagem e operar com ela em seus distintos níveis: textual, pragmático, semântico, sintático, morfológico e fonológico." (GOMBERT, 1992).
} 
trabalho que busque favorecer a consciência do aluno sobre a linguagem utilizada no gênero de leitura proposto, bem como na sua compreensão efetiva, sendo muitas vezes sugeridas tarefas de escrita em gêneros diferentes daquele trabalhado (exemplo: é feita a leitura de uma fábula e se pede um comentário do aluno sobre a mesma).

A respeito do trabalho com a consciência linguística na escola, Spinillo, Mota e Correa (2010), acrescentam que:

\begin{abstract}
Do ponto de vista educacional, parece ser evidente a importância de se desenvolver nos alunos do ensino fundamental, que iniciam a aprendizagem da leitura, uma consciência metalinguística, seja em termos de capacidade de refletir sobre os fonemas de modo a, apoiado no contexto, ser capaz de ler palavras e atribuir-lhes significados; seja em termos de uma consciência a respeito dos morfemas que constituem uma palavra sendo capaz de, ao identificar a palavra que a originou (ou o seu radical, por exemplo), fazer generalizações que permitam ler mais palavras do que aquelas com as quais já tem familiaridade. Essas são, sem dúvida, aquisições relevantes que precisam ser valorizadas e exploradas pela escola a partir de situações em que a criança seja solicitada a tomar os fonemas e os morfemas como objeto de reflexão e análise. (SPINILLO; MOTA; CORREA, 2010, p. 10).
\end{abstract}

A concepção de consciência linguística é ampliada nos estudos atuais de Gombert (2013), que distingue a parte de aprendizagem da escrita, que é implícita, da parte que é explícita, e a relação entre ambos os processos. Ele faz uma clara distinção entre os comportamentos ditos espontâneos, no uso comunicativo habitual da linguagem, conceituados como epilinguísticos, daqueles ditos metalinguísticos, que resultam do controle consciente que o indivíduo realiza sobre os processamentos linguísticos, em suas propriedades formais. Na aprendizagem da escrita, estes últimos são fundamentais.

Gombert pesquisa atualmente a relação dos chamados aprendizados implícitos da escrita, dados pela regularidade do sistema, com aqueles explícitos. Segundo ele, a aprendizagem implícita é "um processo por meio do qual os comportamentos se adaptam progressivamente às características estruturais do meio ambiente com o qual o indivíduo interage sem ter consciência explícita" (idem, 2013, p. 112). Neste caso, são os conhecimentos linguísticos que a criança mobiliza a partir de seu contato com textos, já antes do ingresso na escola, como os fonológicos, morfológicos, e aqueles mais amplos que se referem às regularidades estruturais da língua. Esses conhecimentos linguísticos, pode-se dizer, enquadram-se no conceito de letramento. Já a aprendizagem explícita, consciente, da leitura e da ortografia, a partir da reflexão proposta sobre a escrita, possui o importante papel de permitir ao aluno a construção progressiva de "um 
conjunto de conhecimentos explícitos que ele pode utilizar intencionalmente para completar ou controlar o produto dos processamentos automáticos" (GOMBERT, 2013, p. 119). Dessa forma, é a utilização das regras aprendidas explicitamente na escola que permite rever a resposta automática advinda dos processos implícitos para produzir a ortografia correta. Há, então, de acordo com esse autor, uma dupla vertente no processo de aprendizagem: 1) as aprendizagens implícitas são as responsáveis pelos automatismos de leitura; 2) os conhecimentos conscientes são os que permitem o desenvolvimento dessas aprendizagens no leitor iniciante, e estes são necessários ao leitor proficiente toda vez que ele necessita decidir como realizará sua leitura ou escrita de modo efetivo na língua.

\section{Recursos para avaliar a compreensão de textos na escola}

Em publicação de Farr e Carey (1986) sobre o que pode ser medido em leitura, são apresentadas controvérsias sobre como avaliar a compreensão, por este ser um conceito discutível no meio acadêmico, resultando em dúvidas sobre o que exatamente está sendo medido, sobretudo quando se considera que há diferentes processos cognitivos envolvidos na compreensão. Os testes que solicitam a compreensão literal parecem mais próximos ao conteúdo dos textos; já os testes inferenciais e avaliativos parecem favorecer o uso do conhecimento prévio do leitor (idem, p. 41). Nesse sentido, esses autores consideram que uma boa avaliação precisa assegurar que o examinado compreenda um conceito, fato ou sentimento com base naquele texto específico, mesmo que seu conhecimento prévio possa lhe oferecer respostas (idem, p. 44). Salientam que a interpretação dos dados de um instrumento de compreensão só pode ser aplicada nesse contexto, não sendo adequada sua generalização. Sugerem a administração de mais de um tipo de avaliação e a observação informal em situações mais naturais, porque um teste apenas não reflete todo o comportamento de leitura e de compreensão.

Poersch e Rossa (2007) identificam como recursos utilizados por pesquisadores e professores para avaliar o quanto um leitor compreendeu de um texto a produção de resumos e respostas a questões sobre o mesmo. 0 resumo possibilita um acesso ao modelo cognitivo do texto construído pelo leitor, permitindo supor, na comparação entre o que foi lido e as informações do resumo, o que ele aprendeu a partir do texto. Já 
as perguntas sobre o conteúdo do texto podem alcançar diferentes graus de profundidade de compreensão leitora; podem também levar o leitor a 'ver' e apreender informações que ele poderia não ter compreendido num primeiro momento, desde que elas favoreçam a compreensão não só dos dados explícitos como também das informações contidas nas entrelinhas do texto (idem, p. 61).

Brandão e Spinillo (1998) também apontam que, de modo geral, a compreensão de textos é acessada através de tarefas de reprodução do texto apresentado (lido, ouvido, apresentado em gravuras) ou através de respostas a perguntas sobre ele. Acrescentam que tarefas de reprodução são geralmente aplicadas de forma oral e com crianças pequenas, em forma de reconto da história; enquanto tarefas de perguntas costumam ser propostas a sujeitos mais velhos, envolvendo a leitura de textos. $\mathrm{Na}$ reprodução de narrativas, segundo pesquisa das autoras (idem, 1998), foi observada a capacidade crescente da criança em dois pontos: 1) considerar a história original como um modelo a ser reproduzido, tanto em termos de informação como em estrutura (entre textos); 2) elaborar um texto que apresente integração e unidade (intratexto). Na tarefa de perguntas, este desenvolvimento foi expresso pela precisão crescente nas respostas dadas a perguntas inferenciais, principalmente em relação a partes do texto narrativo consideradas problemáticas, como a resolução e a consequência. As crianças mais novas tiveram maior precisão nas respostas a questões relacionadas à situação-problema, ou seja, ao início da narrativa, do que naquelas relacionadas à resolução e consequência. Já as crianças maiores lograram maior precisão mesmo nas respostas a perguntas que exigiam inferências mais difíceis.

Na análise das especificidades das tarefas propostas nessa pesquisa (BRANDÃO; SPINILLO, 1998), foi observado pelas autoras que a de reprodução é uma atividade de compreensão global, que exige a seleção dos aspectos mais relevantes do texto original e de suas relações essenciais. Aqui cabe citar também, como exemplo, a atividade de elaborar um resumo, utilizado para aferir a compreensão leitora, segundo Spinillo (2009). Já a tarefa de responder a perguntas mostrou-se pontual, pois estas focalizam partes específicas do texto. As perguntas se encarregam de selecionar as informações, no lugar da criança. Assim, em cada tarefa há habilidades cognitivas distintas a serem testadas: na reprodução, habilidades de compreensão mais amplas e integradoras; e nas perguntas inferenciais, aspectos mais específicos da compreensão, particulares a 
determinadas informações e partes do texto (estrutura). Ainda segundo essas autoras, para que a reprodução seja um indicador da compreensão, é imprescindível que esta seja comparada ao texto originalmente apresentado. Elas também ressaltam que não é possível supor um único instrumento para revelar todos os mecanismos envolvidos na compreensão, em conformidade com Farr e Carey (1986). Portanto, é pertinente a utilização de métodos distintos de avaliação da leitura, visto que cada um deles se atém a um aspecto cognitivo da compreensão do sujeito.

Pesquisas experimentais realizadas com crianças de Porto Alegre/RS (WOLFF, 2009; CARVALHO, 2009) replicaram a atividade de perguntas inferenciais para compreensão de história propostas por Brandão e Spinillo (1998), em crianças préescolares de escola privada e pública, respectivamente. Foram criadas outras duas atividades relacionadas ao mesmo texto, a fim de ampliar o espectro de mecanismos cognitivos e linguísticos avaliados. A primeira atividade, aplicada após a leitura da história proposta em interação com cada criança, foi composta de perguntas inferenciais. Após, era apresentada a Tarefa de retirada das figuras não pertencentes à história. Eram mostradas a cada criança sete figuras; duas delas não faziam parte da história, conforme os fatos narrados, e cinco delas se relacionavam aos fatos principais, de acordo com os cinco blocos de conteúdo identificados por Brandão e Spinillo (1998), com base nos estudos de Marcuschi (1989). A outra atividade proposta foi a Tarefa de ordenação das figuras da história e justificativa. Devolvia-se para a criança apenas as figuras pertencentes à história. Então, solicitava-se que ela as ordenasse em sequência, de acordo com a história ouvida. Assim que realizava a tarefa, era solicitada a explicar por que as colocou nessa determinada ordem.

Foi verificado em ambas as pesquisas (WOLFF, 2009; CARVALHO, 2009) que os escores de desempenho entre as tarefas de perguntas e de ordenação de figuras tiveram correlação positiva significativa. Ou seja, quando o desempenho nas perguntas foi superior, tendeu a ser superior também o desempenho na ordenação de figuras. Os resultados da tarefa de retirada de figuras apresentaram correlação razoavelmente positiva com os da tarefa de ordenação de figuras, mas próxima de zero com os da tarefa de perguntas, o que mostrou que o desempenho nessas tarefas pode variar entre si, ou seja, um sujeito pode ter desempenho bom nas perguntas, mas ruim na tarefa de figuras retiradas, e vice-versa. Concluiu-se que as tarefas apresentadas exigiam diferentes vias 
de processamento cognitivo. A tarefa de perguntas inferenciais partia da seleção verbal de determinadas partes do texto pelo avaliador, sendo mais pontual e específica, conforme Brandão e Spinillo (1998); a de ordenação das figuras e justificativa partia de um estímulo visual manipulado pelo avaliado, exigindo a recordação da história ouvida: a criança é que precisava selecionar, na história, o que estava por trás da imagem apresentada e encontrar a ordem de causalidade dos fatos, necessitando acessar seu esquema global da história. Esta tarefa, que dependia da associação da imagem com o esquema cognitivo global da história desenvolvido pelo sujeito, parece ter oferecido mais possibilidades a ele para inserir ou excluir elementos da história, a fim de ligar os fatos lembrados, aproximando-se mais de uma tarefa de reprodução, que também considera o texto como um todo. Esse desafio pode exigir maior interação de conhecimentos prévios da criança pré-escolar com relação ao conteúdo da história para o desenvolvimento de uma justificativa coerente e que possa 'resolver' as falhas de recordação.

Importante destacar que a avaliação da leitura durante a alfabetização em escolas públicas é contemplada, no Brasil, na Avaliação da Alfabetização Infantil, através da Provinha Brasil 5 , que é elaborada e distribuída pelo Inep ${ }^{6}$ (Instituto Nacional de Estudos e Pesquisas Educacionais Anísio Teixeira), em caráter oficial e nacional, para verificar o nível de alfabetização e letramento inicial dos alunos do segundo ano do Ensino Fundamental I, sendo aplicada no início e no final deste ano escolar. São seis os descritores (D) para avaliar as habilidades de leitura neste instrumento de verificação: D4 - ler palavras; D5 - ler frases; D6 - localizar informação explícita em textos; D7 reconhecer assunto de um texto; D8 - identificar a finalidade do texto; D9 - estabelecer relações entre partes do texto; D10 - inferir informação.

Já alunos maiores, em torno de 15 anos, são avaliados pelo Pisa7 (Programa Internacional de Avaliação de Estudantes). Nessa faixa etária, na maioria dos países, os estudantes já completaram a escolaridade obrigatória. Este programa é desenvolvido e coordenado pela Organização para Cooperação e Desenvolvimento Econômico (OCDE), e

\footnotetext{
${ }^{5}$ Maiores detalhes sobre a Provinha Brasil: http://portal.inep.gov.br/web/provinha-brasil/provinhabrasil e http://download.inep.gov.br/educacao basica/provinha brasil/matriz referencia/2009/matriz de referencia provinha brasil.pdf

${ }^{6} 0$ presente artigo propõe-se apenas a apresentar esses testes e não entrar no mérito da discussão de sua composição, resultados e validade (nota das autoras).

7 Maiores detalhes sobre o Pisa: http://download.inep.gov.br/acoes internacionais/pisa/marcos referenciais/2013/matriz avaliacao leitura.pdf
} 
no Brasil é também coordenado pelo Inep. Há um corte a partir dos alunos que estão cursando pelo menos o Grau 7 (7th grade). No Brasil isso corresponde aos alunos matriculados acima do $8^{\text {o }}$ ano (7 $7^{\text {a }}$ série) do Ensino Fundamental até o final do Ensino Médio. As avaliações do Pisa acontecem a cada três anos e abrangem três áreas do conhecimento - Leitura, Matemática e Ciências - havendo, a cada edição do programa, maior ênfase em cada uma dessas áreas. Das estratégias de leitura avaliadas pelo teste, são destacadas três (item 1.4 da Matriz de Avaliação de Leitura) e uma quarta que engloba as demais: localizar e recuperar informação (localizar no espaço do texto e selecionar uma informação solicitada); integrar e interpretar (realizar a conexão de diversas partes do texto ou de diferentes textos para que adquiram significado e construir significado a partir de algo que não está explícito no texto ou em parte dele); refletir e analisar (consultar as próprias experiências para comparar, contrastar ou traçar hipóteses e realizar julgamentos elaborados a partir de padrões que vão além do texto apresentado); complexo (inclui atividades de texto digital, caracterizadas pela maior liberdade de uso de estratégias para compreensão que esse meio permite).

\section{Implicações pedagógicas}

A partir dos conceitos trazidos neste trabalho quanto ao desenvolvimento do processo de compreensão leitora e de como são ativadas diferentes habilidades cognitivo-linguísticas nos processos avaliativos, são aqui tecidas algumas considerações sobre as implicações pedagógicas desses aspectos para o percurso escolar.

Os processamentos ascendente e descendente de leitura devem ser estimulados de forma integrada pela escola já a partir da alfabetização, contribuindo para que os alunos desenvolvam sua capacidade leitora em direção a leituras que exigem inferências cada vez mais elaboradas, levando em conta a progressão do entendimento das diferentes partes do texto, por exemplo. Para isso, os aspectos linguísticos expressos no texto, em seus diferentes níveis, necessitam ser trabalhados pelo professor com os alunos de modo explícito, para que estes conhecimentos formais possam ser desenvolvidos na escrita e na leitura.

Muitas vezes, o aluno utiliza mais de seus conhecimentos prévios do que das informações textuais, perdendo a oportunidade de desenvolver esquemas mentais mais 
complexos, que podem ser estimulados através de recontos, resumos e paráfrases. Os diferentes níveis linguísticos do texto e as diferentes estratégias cognitivas mobilizadas pelo aluno, de acordo com a atividade proposta, precisam ser levados em conta também no processo de ensino/avaliação, propondo-se atividades diversificadas, que estimulem e desenvolvam diferentes estratégias cognitivas e caminhos de compreensão. Porém, deve-se reconhecer nas atividades propostas o que cada uma traz de desafio peculiar para o aluno, pois isto permitirá reavaliar propostas de forma mais consistente.

Alguns questionamentos que se pode fazer acerca das atividades em sala de aula são: é uma atividade que utiliza prioritariamente conhecimentos prévios? A tarefa proposta convida a relacionar ideias e a realizar inferências? Ou conduz o aluno pela superfície do texto e solicita apenas informações explícitas? Exige um esquema global do que foi lido? Propõe a reflexão sobre aspectos pontuais do texto? É importante que o professor, ao planejar seu rol de tarefas com os alunos, tenha em mente seus possíveis desdobramentos. A predição também é exercida no planejamento das aulas, não somente durante a leitura propriamente dita.

Cada fazer na escola implica em metas a alcançar, e, assim como a leitura em si precisa de objetivos, segundo Goodman (1991), a proposição de atividades não está isenta desse foco. 0 objetivo proposto no trabalho textual é bastante significativo para indicar os caminhos de compreensão que os alunos percorrerão no texto. As questões a serem respondidas pelo professor a respeito dessa atividade, e que se refletirão nas propostas feitas aos seus alunos, podem ser: propõe identificar informações relevantes para outra atividade que será desenvolvida? Propõe crítica ao que é escrito? Propõe que se identifiquem características linguísticas de algum gênero, como humor, por exemplo? Os objetivos de leitura têm significativa influência no tipo de inferência que o leitor irá realizar, em função das informações que seleciona para satisfazer seu objetivo de leitura.

Como resposta a um processo que na escola é tomado muitas vezes como lógico e espontâneo, Spinillo (2013) propõe que a compreensão leitora na sala de aula deva ser desenvolvida "de forma mais específica, e não apenas como um subproduto da alfabetização, como se a compreensão fosse uma consequência direta e inevitável da aprendizagem do sistema de representação da escrita" (idem, p. 151). Essa autora ressalta que se deve privilegiar um tratamento didático da compreensão que contemple suas especificidades, e que essa abordagem deve levar em conta o trabalho com a 
construção de significado e a integração de informações do texto na forma de atividades metalinguísticas e metacognitivas - respectivamente, o olhar do aluno sobre o texto e sobre o próprio pensamento.

A escola, na pessoa do professor de ensino fundamental, precisa de um aporte teórico bem fundamentado em pesquisas que efetivamente colaborem positivamente para o seu trabalho diário com o conhecimento dos alunos. As contribuições de Gombert (2013) sobre conhecimentos explícitos e implícitos na aprendizagem da escrita, por exemplo, trazem como implicação pedagógica a necessidade de a instituição de ensino proporcionar de forma organizada os conhecimentos conscientes que possibilitem ao aluno aplicar voluntariamente os procedimentos e estratégias de leitura e de escrita, organizando aquilo que ele já possui como conhecimento espontâneo. Também o incentivo à manipulação frequente da leitura e da escrita é fundamental para que possam se instalar os automatismos, alimentando sua prática progressivamente.

Na concepção de aprendizagem de leitura proposta por Pereira (2010; 2012), como referido no item 2 deste artigo, a atividade de escrita deve partir do mesmo gênero textual trabalhado. Ou seja, as atividades de compreensão leitora exigem uma exploração textual consciente, onde os aspectos linguísticos necessitam ser amarrados a partir do texto e do gênero em questão para a construção de sentido. É necessário que o trabalho com gêneros seja, de certa forma, esgotado junto ao aluno, para se criarem condições de posteriormente, em sala de aula, reuni-los em atividades que congreguem os mais variados modos de dizer e de escrever, e estimular os aprendizes a transitar com desenvoltura entre os diferentes gêneros.

0 trabalho com resumos, nesse caso, pode se mostrar um bom instrumento tanto de avaliação da compreensão como de auxílio no entendimento dos textos dos mais diversos gêneros (SPINILLO, 2009). É interessante que, de início, ele normalmente é abordado em aula como tarefa prática, quando o professor deveria apresentá-lo como objeto de estudo, primeiramente tornando-o foco de uma prática que integra leitura e escrita. A exigência metalinguística de elaboração de um texto baseado em um textofonte como base é de grande auxílio como guia para o aprendizado das estruturas comuns a todos os gêneros possíveis - o texto-fonte serve de exemplo para a construção de um segundo texto, sem se perder a carga semântica e descaracterizar o estilo do original. Assim, ele é um gênero peculiarmente atrelado a outros - história, relato, 
telefonema, notícia, por exemplo - e cuja assimilação pelo aluno poderá ser um passo significativo no caminho de uma produção textual independente.

Outro instrumento de avaliação e também de trabalho em aula é a paráfrase, que evidencia ainda mais a autonomia do leitor-escritor quando este utiliza suas próprias palavras para criar outro texto, seja ele uma história, notícia, dissertação etc. Conforme Kleiman (1995, p. 83), a habilidade em fazer paráfrases de um texto está entre as postuladas por alguns psicólogos e educadores que abordam a leitura. Essa habilidade decorre do uso apropriado de estratégias de processamento. Além disso, essa paráfrase vai além da compreensão de pistas locais no texto, envolvendo a "percepção global e a transformação dos elementos locais em um todo coerente". A autora cita como demonstração da capacidade de percepção da estrutura do texto: 1) a depreensão do tema; 2) a construção de relações lógicas e temporais; 3) a construção de categorias superestruturais ou relacionadas ao gênero textual; e 4) a percepção das relações de hierarquização entre as informações do texto. Entretanto, uma paráfrase não é um resumo, pois não tem a fidedignidade ao texto original - apenas ela demonstra um potencial criativo do leitor-escritor, muito importante no uso de recursos diversos dos utilizados no texto-fonte pelo autor.

\section{Considerações finais}

Refletindo sobre os processos de compreensão de leitura a partir dos itens destacados neste trabalho, pode-se concluir que são muitos os aspectos envolvidos no processamento e na compreensão da leitura e que estes devem ser levados em conta no seu ensino e na sua avaliação. Para a avaliação, especialmente, verifica-se que é possível acessar diferentes aspectos da compreensão de acordo com a tarefa proposta, pois diferentes estratégias cognitivas são colocadas em ação de acordo com os objetivos de análise de um texto - se por perguntas inferenciais ou de múltipla escolha, por reprodução através de resumos, por ordenação de fatos, por identificação do que faz parte ou não das informações do texto, por exemplo.

O ensino da leitura na escola deve levar em conta a associação dos diferentes níveis linguísticos do texto (aspectos fônicos, mórficos, sintáticos, semânticos e pragmáticos) e a construção de sentidos coerentes com aquilo que o autor diz. Desse 
modo, pode-se favorecer a consciência do aluno sobre a língua, proporcionando condições para que sua leitura se torne competente e que ele desenvolva autonomia nos processos de construção do pensamento, aprendendo a aprender e gerir seu conhecimento. Assim, a partir da compreensão efetiva do texto, há uma real ampliação de esquemas cognitivos e linguísticos, maior relação entre conceitos internalizados e o desenvolvimento de possibilidades críticas consistentes por parte do aluno.

\section{Referências}

BARRERA, Sylvia Domingos. Papel facilitador das habilidades metalinguísticas na aprendizagem da linguagem escrita. In: MALUF, Maria Regina (org.). Metalinguagem e aquisição da escrita - contribuições da pesquisa para a prática da alfabetização. São Paulo: Casa do Psicólogo, 2003.

BRANDÃO, Ana Carolina P.; SPINILLO, Alina G. Aspectos gerais e específicos na compreensão de textos. Psicol. Reflex. Crit. [online], v. 11, n. 2, p. 253-272, 1998.

CARVALHO, Queiti. Desenvolvimento semântico e compreensão de história em crianças de cinco e seis anos. Dissertação (Mestrado em Letras, área de concentração de Linguística Aplicada). Faculdade de letras, Pontifícia Universidade Católica do Rio Grande do Sul, 2009.

COLOMER, Teresa; CAMPS, Anna. Ensinar a ler, ensinar a compreender. Tradução: Fátima Murad. Porto Alegre: Artmed, 2002.

DAHAENE, Stanislas. Os neurônios da leitura: como a ciência explica a nossa capacidade de ler. Tradução: Leonor Scliar-Cabral. Porto Alegre: Penso, 2012.

FARR, Roger; CAREY, Robert. Reading: what can be measured? 2ed. Newark: IRA, 1986.

GOMBERT, Jéan-Émile. Metalinguistic development. Hertfordshire: Harverster Wheatsheaf, 1992.

. Epi/meta versus implícito/explícito: nível de controle cognitivo sobre a leitura e sua aprendizagem. In: MALUF, Maria Regina; CARDOSO-MARTINS, Cláudia (Orgs.) Alfabetização no século XXI - como se aprende a ler e a escrever. Porto Alegre: Penso, 2013.

GOODMAN, Kenneth. Reading: a psycholinguistic guessing game. In: SINGER, Harry, RUDDELL, Robert. Theoretical models and process of reading. Newark, DE: International Reading Association, 1976.

. Unidade na leitura - um modelo psicolinguístico transacional. Letras de Hoje. Porto Alegre, v. 26, p. 9-43, dez/1991. 
INSTITUTO NACIONAL DE ESTUDOS E PESQUISAS EDUCACIONAIS ANÍSIO TEIXEIRA (INEP). Disponível em http://portal.inep.gov.br/home - acesso em 25 de maio de 2014.

KATO, Mary A. No mundo da escrita - uma perspectiva psicolinguística. 7ed. São Paulo: Ática, 1990. O aprendizado da leitura. 6 ed. São Paulo: Martins Fontes, 2007.

KLEIMAN, Angela. Oficina de leitura - teoria e prática. Campinas, SP: Pontes: Editora da Universidade Estadual de Campinas, 3aㅡ ed, 1995.

LEFFA, Vilson. Aspectos da Leitura - uma perspectiva psicolinguística. Coleção Ensaios. Porto Alegre: Sagra-Luzzatto, 1996.

KLEIMAN, Ângela. Leitura: ensino e pesquisa. Campinas: Pontes, 1989.

MARCUSCHI, Luiz A. O processo inferencial na compreensão de textos. Relatório final apresentado ao CNPq. Programa de Pós-Graduação em Letras e Linguística, Universidade Federal de Pernambuco, Recife, 1989.

PEREIRA, Vera Wannmacher. Aprendizado da leitura e consciência linguística. Anais do IX Encontro do CELSUL. Palhoça, SC, Universidade do Sul de Santa Catarina. Out, 2010.

PEREIRA, Vera Wannmacher; SCLIAR-CABRAL, Leonor. Compreensão de textos e consciência textual - caminhos para o ensino nos anos iniciais. Florianópolis, Insular, 2012.

POERSCH, José Marcelino; ROSSA, Adriana (org.) Processamento de Linguagem e Conexionismo. Santa Cruz do Sul: EDUNISC, 2007.

SMITH, Frank. Compreendendo a Leitura. 4ª ed. Porto Alegre: Artmed, 2003.

SPINILLO, Alina Galvão. "Eu sei fazer uma história ficar pequena" - a escrita de resumos por crianças. Interamerican Journal of Psychology, v. 43, n. 2, 2009, p. 362-373.

Alfabetização e consciência metalinguística: a leitura da palavra à leitura do texto. In: MALUF, Maria Regina; CARDOSO-MARTINS, Cláudia (Orgs.) Alfabetização no século XXI - como se aprende a ler e a escrever. Porto Alegre: Penso, 2013.

SPINILLO, Alina Galvão; MAHON, Érika da R. Compreensão de texto em crianças: comparações entre diferentes classes de inferência a partir de uma metodologia online. Psicol. Reflex. Crit. [online], v. 20, n. 3, p. 463-471, 2007.

SPINILLO, Alina Galvão; MOTA, Márcia Maria Peruzzi Elia da; CORREA, Jane. Consciência metalinguística e compreensão de leitura: diferentes facetas de uma relação complexa. Educar em Revista, Curitiba: Editora UFPR, n. 38, p. 157-171, set./dez. 2010. 
WOLFF, Clarice L. Compreensão de história e consciência fonológica de crianças préescolares. Dissertação (Mestrado em Linguística Aplicada) - Faculdade de Letras, Pontifícia Universidade Católica do Rio Grande do Sul, 2009.

Recebido em março de 2014.

Aceito em junho de 2014. 